\title{
Raman and Fluorescence Studies of Thermotropic Liquid-Crystalline Oligomers with Different Type of Coils
}

\author{
Jong-Bok Chae, Soo-Chang Yu, and Younsik Lee \\ Department of Chemistry, Kunsan National Lnwersity Kunsan, Chonbuk 573-701, Korea. "E-mail: scutakunsanackr \\ ${ }^{\dagger}$ Division of Enwironmental and Chemical Engineering. The Research Center of Industrial Technologv, \\ Chonbuk National Linversitv, Chonju 561-756, Korea \\ Received November 13, 2006
}

\begin{abstract}
Raman and fluorescence spectroscopies were employed to study the coil effects on the intermolecular stnucture of a rod-coil liquid crystalline (LC) oligomer. the esterification products of ethyl 4-[4'-oxy-4-bipheny]carbony loxy]-4'-biphenylcarboxylate with poly (propylene)oxides ( $\mathrm{PPO})(\mathrm{DP}=12)$ and poly (ethylene oxide)s $(\mathrm{PEO})(\mathrm{DP}=12)$. Three different vibrational modes (carbonyl, aromatic $\mathrm{C}-\mathrm{H}$. and aromatic $\mathrm{C}=\mathrm{C}$ ) obtained from the Raman experiment at variable temperature indicate that $\mathrm{PPO}$ and $\mathrm{PEO}$ coils induce the hydrogen bonding in a different manner. Further information about the micro-environment around the mesogenic unit obtained by fluorescence excitation spectra of P 2-4 (LC with PPO coil) and 12-4 (LC with PEO coil) suggests that the mesogenic unit of P12-4 is quite different from that of 12-4 in intermolecular stnucture. This study supports the results obtained only from Raman spectroscopy'. providing more accurate information about the intermolecular stnictural changes of liquid crystalline poly'mers at a molecular level during the phase transitions.
\end{abstract}

Key Words : Raman. Fluorescence. Liquid cry stalline. Intermolecular structure, Coil effect

\section{Introduction}

Liquid crystalline polymers (LCPs) have been intensively studied for their scientific and technological interests. Among LCPs rod-coil types have recently drawn attention. particularly in relation to their likelihood to form various kinds of supramolecules depending on chain lengths. ${ }^{1-4}$ The LCPs based on a biphenyl ester moiety can have different microscopic structures. Most poly(ethylene oxide)s (PEO)-based LCPs result in a layered smectic mesophase. ${ }^{5}$ whereas poly(propy lene oxide)s (PPO)-based LCPs give rise to a layered smectic C. smectic A. biconticuous cubic. and hexagonal columnar mesophases depending on the chain lengths. ${ }^{6}$ Considering the fact that the physical properties of LCPs are mainly characterized by the molecular interactions between the mesogenic moieties. the molecular-based information about the coil effects on the molecular interactions between the mesogenic moieties is very important in providing an insight into the mechanism for the formation of supramolecules. $^{7}$

Fluorescence spectroscopy is among the most widely used optical methods to study intermolecular interactions between neighboring molecules with aromatic rings. Enormous efforts have been undertaken to investigate the intermolecular structure of LCPs using the fluorescence technique by Horie et al. ${ }^{8-12}$ They utilized fluorescence spectroscopy to elucidate the intermolecular interaction of biphenyl-related LC polymers. Various kinds of intermolecular ground state complex were revealed with the help of highly sensitive fluorescence teclunique.

Although it is highly sensitive to the intermolecular structure as to detect only' small differences in the chain lengths. this method is limited in yielding information regarding the specific sites involved in the intermolecular interactions Vibrational spectroscopy such as Raman is considered among the most efficient tools for this purpose. providing rich information on a molecular level. ${ }^{13-18}$ In this context. we utilized both Raman and Fluorescence techniques to characterize the conformational and structural changes as sitespecific and sensitive methods.

In order to study the coil effects on the intermolecular structure. we have chosen a rod-coil liquid crystalline oligomer(P12-4) with twelve PPO units as a coil and compared its results with those of 12-4 with twelve PEO units. the esterification products of ethyl 4-[4'-oxy-4-biphenylcarbonyloxy]-4'-biphenylcarboxylate with $\mathrm{PPO}(\mathrm{DP}=12)$ and with $\mathrm{PEO}(\mathrm{DP}=12)$. To this end three different vibrational modes (carbonyl. aromatic $\mathrm{C}-\mathrm{H}$ and aromatic $\mathrm{C}=\mathrm{C}$ ), and the excitation profiles were monitored by Raman and fluorescence spectroscopies. respectively. The combination of two techniques should provide complementary and accurate information about the intermolecular structure in the crystalline phase.

\section{Experimental Parts}

The details of the synthesis and characterization of $\mathrm{P} 12-4$ and $12-4$ were reported in a previous publication. ${ }^{5.6}$ and their chemical structures are shown in Figure 1. The crystalline to $\mathrm{LC}(\mathrm{K}-\mathrm{LC})$ phase transition temperatures (first heating at a rate of $10^{\circ} \mathrm{C} \mathrm{min}{ }^{-1}$ ) were observed at $36.9^{\circ} \mathrm{C}$ and $135.2^{\circ} \mathrm{C}$. for P12-4 and 12-4, respectively. from a Perkin Elmer DSC7 differential scanning calorimeter (DSC) equipped with a 1020 thermal analy sis controller.

The Raman spectra were obtained using a Renishaw Raman micro sy'stem 2000 with the 632.8-1nm line of a $\mathrm{HeNe}$ laser as excitation source ${ }^{15.16 .19}$ The laser power at the sample 
<smiles>[2H]C(C)(CCOC(C)(C)c1ccc(-c2ccc(C(=O)Oc3ccc(-c4ccc(C(=O)OCC)cc4)cc3)cc2)cc1)OC</smiles>

(b)

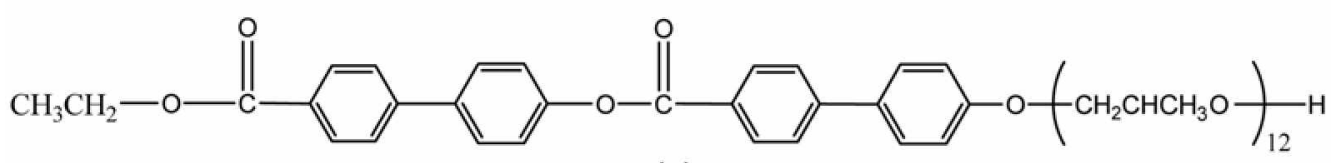

(a)

Figure 1. The chemical structures of (a) P12-4 and (b) 12-4.

was ca. $5 \mathrm{~mW}$ and the resolution of the spectra was within $\pm 2 \mathrm{~cm}^{-1}$. Putting the samples on glass slides, the data were acquired by using a Linkam heating and freezing stage (THMSE 600) with a controller (TMS 92), and then calibrated to the silicon band at $521 \mathrm{~cm}^{-1}$.

The fluorescence spectra were obtained using a Timemaster (PTI) ${ }^{2 i}$ coupled with a optical fiber suitable for measurement from the horizontal stage. THMSE 600. The reflection mode from the horizontal stage rendered us to take spectra at variable temperature while minimizing selfabsorption. The fluorescence excitation was scanned while monitoring emission at $380 \mathrm{~mm}$. The integration time was 1 sec. with $2 \mathrm{~nm}$ as a step scan.

\section{Results and Discussion}

Raman and fluorescence studies of P12-4 and 12-4 were performed to determine the intermolecular interaction at the molecular level. With the fingerprinting capability of Raman spectroscopy. the change in the specific functional groups was elaborately monitored. The complementary disclosure about the intermolecular interactions between the mesogenic units was also made by using fluorescence spectroscopy

We first considered carbonyl modes in Raman spectra. Nomally there are only two carbonyl bands in the spectra of both P12-4 and 12-4 unless intermolecular interactions exist. The two carbonyl groups in each molecule are surrounded by different environments. retaining a different force constant around the $\mathrm{C}=\mathrm{O}$ bond. Of the two bands the low wavenumber band corresponds to the $\mathrm{C}=\mathrm{O}$ group between the biphenyl moieties. while the high wavenumber band corresponds to the $\mathrm{C}=\mathrm{O}$ group near the ethyl terminal ${ }^{16}$ For both Pl2-4 and 12-4. however. three bands, 1709, 1715. 1731 $\mathrm{cm}^{-1}$ for Pl2-4, and 1717. 1725. $1734 \mathrm{~cm}^{-1}$ for $12-4$ were observed at low temperatures as can be seen in Figure 2. indicating the existence of intemolecular interactions in the crystalline phases.

The locations of the two free carbonyl bands for P12-4 should be nearly the same as those of $12-4$ since the two molecules have the same mesogenic units. Therefore the bands at $1715 \mathrm{~cm}^{-1}$ and $1717 \mathrm{~cm}^{-1}$ for P12-4 and for $12-4$. respectively, are assignable to the $\mathrm{C}=\mathrm{O}$ groups between the biphenyl moieties. whereas the bands at $1731 \mathrm{~cm}^{-1}$ and 1734 $\mathrm{cm}^{-1}$ for P12-4 and for $12-4$. respectively, to the $\mathrm{C}=\mathrm{O}$ groups

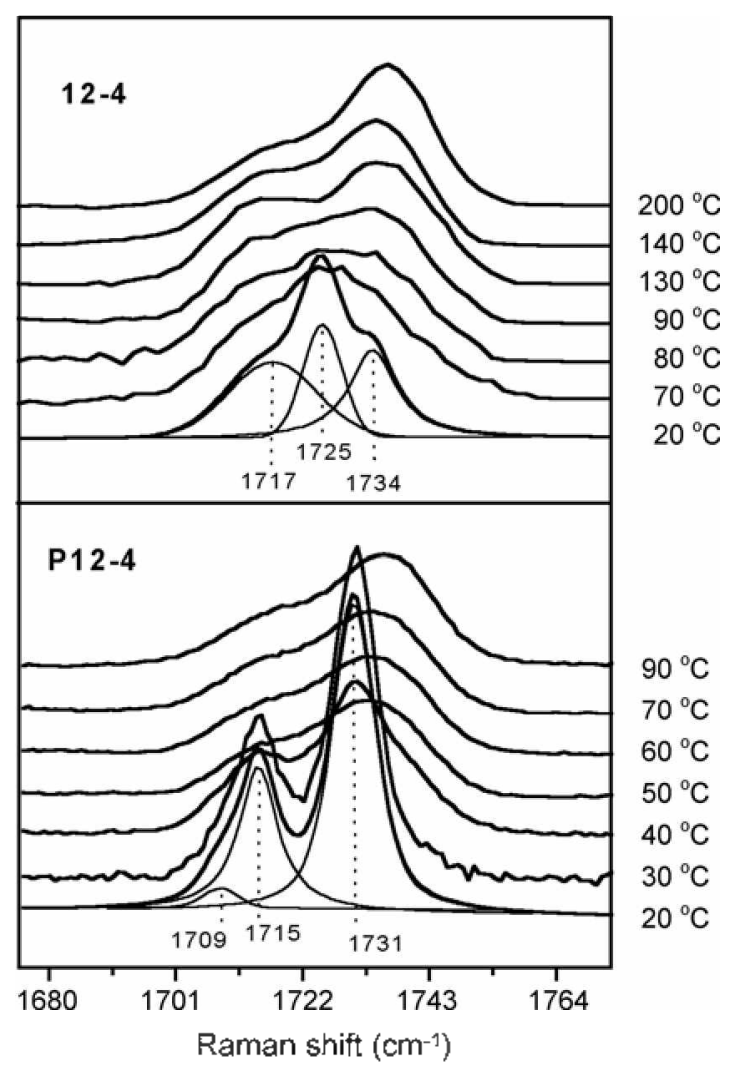

Figure 2. Temperature dependence of the carbonyl modes for P124 (bottom ) and 12-4 (top). The three solid lines are obtained through curve-fitting of the conesponding spectrum at $20^{\circ} \mathrm{C}$.

near the ethyl terminal. Accordingly, the bands at $1709 \mathrm{~cm}^{-1}$ and $1725 \mathrm{~cm}^{-1}$ for $\mathrm{P} 12-4$ and $12-4$, respectively. can be assigned to the hydrogen bonded carbonyl modes. Considering the fact that the $\mathrm{C}=\mathrm{O}$ band shifts to lower wavenumbers upon hydrogen bonding. ${ }^{17}$ the band at $1709 \mathrm{~cm}^{-1}$ originates from the $\mathrm{C}=\mathrm{O}$ group between the biphenyl moieties. whereas the band at $1725 \mathrm{~cm}^{-1}$ originates from the $\mathrm{C}=\mathrm{O}$ group near the ethyl terminal.

It is noteworthy that the $\mathrm{C}=\mathrm{O}$ band at higher frequency shifts abruptly around the phase transition temperature for $\mathrm{P} 12-4$ (compare the spectrum at $40^{\circ} \mathrm{C}$ with that at $50^{\circ} \mathrm{C}$ ), ${ }^{21}$ whereas that of 12.4 sluifts gradually over the entire temperature range. This seems to be mainly due to the different disruption mechanisn for intermolecular interactions during 


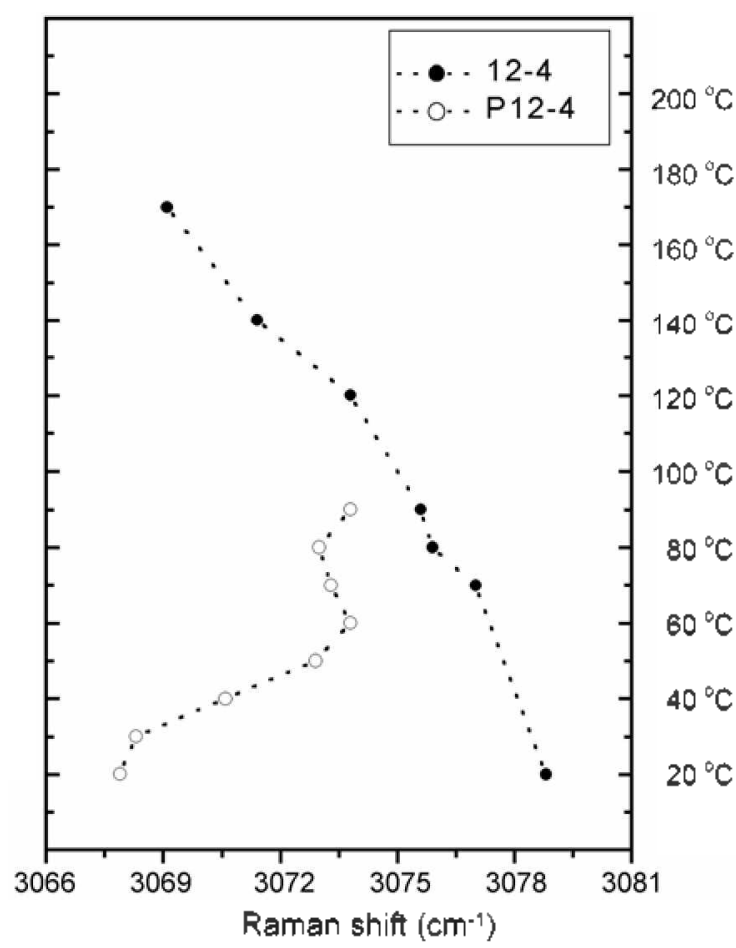

Figure 3. Temperature dependence of the $\mathrm{C}-\mathrm{H}$ stretching modes for P12-4 (:- ) and $12-4(\bullet)$

phase transitions. According to our previous results, the carbonyl group near the ethyl terminal was easier to rotate than the one between the biphenyl groups during the phase transition ${ }^{16}$ Therefore. the bond rotation about the aromatic $\mathrm{C}-(\mathrm{C}=\mathrm{O})$ is gradually followed by bond breaking. resulting in the continuous frequency shift owing to the conformational change for 12-4. On the other hand as the hydrogen bonding is broken down. only the distance between the neighboring mesogens changed without giving rise to bond rotation about the aromatic $\mathrm{C}-(\mathrm{C}=\mathrm{O})$ (between the biphenyl moiety) participating in the hydrogen bonding for P12-4. Accordingly: the frequency shift is not developed above $50^{\circ} \mathrm{C}$. the phase transition temperature, which is slightly different from DSC measurement. but is reasonably acceptable.

The above argument can be clarified by the counterpart of the $\mathrm{C}=\mathrm{O}$ group involved in the hydrogen bonding. This is supported by the observation of the temperature dependent behavior of the aromatic $\mathrm{C}-\mathrm{H}$ stretching modes. Assuming that one of the aromatic hydrogen atoms is responsible for the hydrogen bonding, the aromatic $\mathrm{C}-\mathrm{H}$ stretcling mode is. then anticipated to shift to a higher frequency upon breaking down the hydrogen bonding since the weakened $\mathrm{C}-\mathrm{H}$ bond will be reinforced. The result for P12-4 showed that the frequency shift to higher wavenumbers from $3068 \mathrm{~cm}^{-1}$ in the crystalline phase to $3074 \mathrm{~cm}^{-1}$ in the molten is consistent with our assumption (Figure 3). The result for 12-4. however. shows the reverse direction to lower wavernumber. ruling out the hydrogen bonding with the aromatic hydrogen atoms. The downward frequency shift of this aromatic C-H stretching band from 3078 to $3069 \mathrm{~cm}^{-1}$ is found to be due to expansion of the packing structure. ${ }^{23}$ The possibility of the

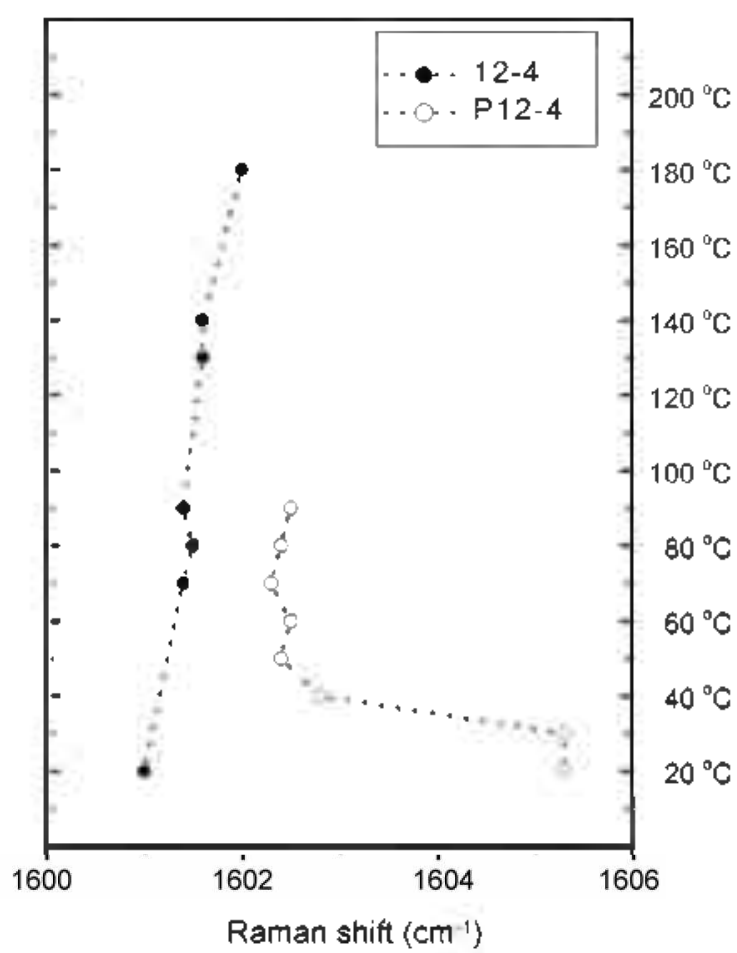

Figure 4. Temperature dependence of the $\mathrm{C}=\mathrm{C}$ stretching modes for PI2-4 ( -$)$ and $12-4(\bullet)$.

hydrogen bonding of the $\mathrm{C}=\mathrm{O}$ group with one of the hydrogen atoms of the PEO group for 12-4 was suggested in our previous report. ${ }^{16}$ and is confirmed through the observations described above.

This can be further confinmed by observing the $\mathrm{C}=\mathrm{C}$ stretching mode. The aromatic $\mathrm{C}=\mathrm{C}$ band displays a downward shift in frequency for P12-4. whereas it display's an upward shift for 12-4 (Figure 4). Considering the fact that a downward shift in frequency of the $\mathrm{C}=\mathrm{C}$ band is generally due to the decrease in the inter-chain force constant. ${ }^{17,18}$ the downward shift for P12-4 seems to be due to the decrease in the force constant about the $\mathrm{C}=\mathrm{C}$ bond. probably resulting from the formation of the conjugation between the neighboring mesogens. In the crystalline phase. hydrogen bonding is formed through the carbonyl bond between the biphenyl moieties with the adjacent aromatic hydrogen atom. maintaining a certain distance between neighboring mesogens. As the hydrogen bonding is broken down at the phase transition temperature, this distance becomes closer. resulting in a $\pi-\pi$ stacking between neighboring mesogens by either partial or full overlapping. Thus the $\pi-\pi$ stacking causes the frequency shift to lower wavenumber since the $\pi$ electrons of the benzene ring participating in the $\pi-\pi$ stacking reduce the force constant of the $\mathrm{C}=\mathrm{C}$ bond. The upward shift in 12-4 can be explained by a quite opposite interpretation. It seems that the $\pi-\pi$ stacking formed between the biphenyl groups below the phase transition temperature becomes loosened upon reaching the phase transition temperature giving rise to the upward shift. As is the case for the aromatic $\mathrm{C}-\mathrm{H}$ stretching mode. the frequency shift occurs only during the phase transition for P12-4, while it 


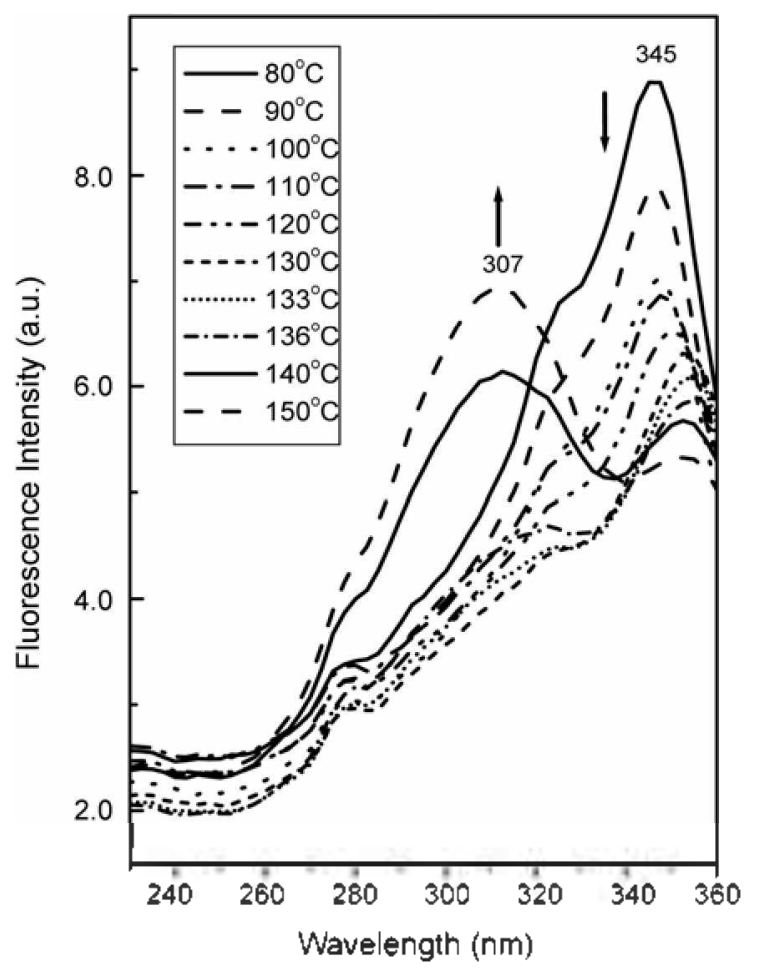

Figure 5. Temperature dependence of fluorescence excitation spectra for $12-4$.

occurs monotonously with increasing tentperature for 12-4.

Fluorescence excitation spectroscopy was employed to support the above arguments. The main advantage of excitation method exists in the fact that it reflects the electronic ground state configurations of the molecule and thus represents the distribution of absorbing species in the absence of structural perturbations that arise from electronic excitation. ${ }^{23}$ Therefore. its results are comparable to Raman results. which were mostly attributed to the electronic ground state intermolecular complex. It is noteworthy to understand the features of fluorescence spectroscopy in amorphous polymer. For the themmotropic liquid crystalline polymers or oligomers. the overlapping between the mesogenic moieties in the adjacent molecules is continuously changing with increasing temperature. Consequently. the distance between the mesogenic moieties becomes closer or farther depending on the pattern of intermolecular interactions as they are broken down at the phase transition temperature. This. in turn. results in a change in a $\pi-\pi$ stacking. thus a shift of the fluorescence excitation to either a longer or shorter wavelength.

Horie et $\mathrm{al}^{12}$ found the changes in the fluorescence profile with varying temperature in a rod-coil polyester with flexible side chains. and ascribed them to the different distance between the electron donor and acceptor groups. This is true for our molecules. The fluorescence excitation spectra for $12-4$ (Figure 5) were obtained by monitoring the fluorescence emission at $380 \mathrm{~nm}$. Considering the spectral pattern with respect to the temperature. the band between $340 \mathrm{~mm}$ and $350 \mathrm{~nm}$ could be attributed to the intemolecular ground-state complex (dimer) between the biphenyl and the

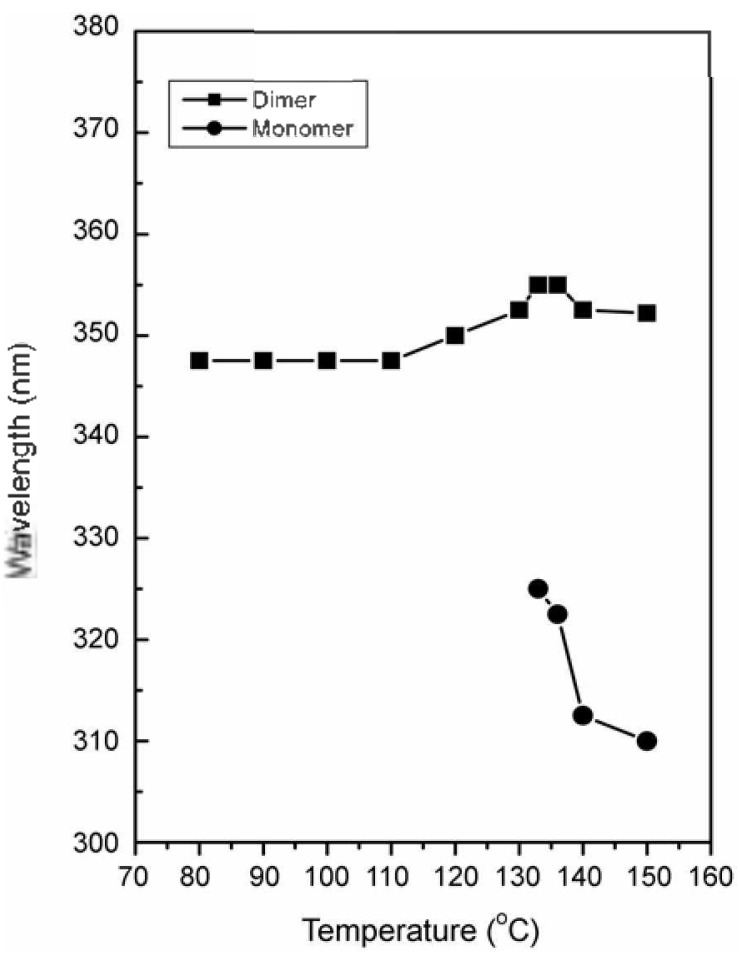

Figure 6. Temperature dependence of excitation peaks for 124.

ester groups in the adjacent molecular axes. The frequency shift from $345 \mathrm{~nm}$ to $354 \mathrm{~nm}$ occurred continuously before the K-LC phase transition temperature at $135.2^{\circ} \mathrm{C}$ (Figure 6). This may indicate that the biphenyl moieties between adjacent molecules are getting closer to each other until the bond breaking occurs presumably through the rearrangement between the adjacent molecules. Accordingly, the conjugation between two biphenyl moieties are formed resulting in a lower excitation energy. As the temperature increased further. a new band appeared at around $307 \mathrm{~nm}$ while the longer one disappeared. This means that the distance between the adjacent molecules is getting farther. resulting in a monomer eventually. Horie et al ${ }^{12}$ observed the fluorescence spectrum for the monomer molecule of biphenyl or pyromellitic ester moieties at shorter wavelength than the polymer with these units. They ascribed the fluorescence spectrum at longer wavelength to the intermolecular ground state complex between the biphenyl group and the ester group. This phenomenon is quite in good agreement with our fluorescence as well as Raman studies. To further confirm that the spectrum at $307 \mathrm{~nm}$ is attributed to the monomer, we acquired the spectrum of 12-4 in a methyl cluloride (MC) solution. As can be seen in Figure 7, the band appeared at $300 \mathrm{~nm}$ in a diluted solution. which is very close to $307 \mathrm{~nm}$.

The fluorescence excitation profile for P12-4 is quite opposite to that of 12-4. The fluorescence excitation spectra at 2 ' $\mathrm{C}$ ' interval were obtained by monitoring the fluorescence emission at $370 \mathrm{~mm}$ for P12-4, and displayed in the range between 240 and $350 \mathrm{~nm}$ as can be seen in Figure 8 . As temperature increases the intensity gradually decreases. 


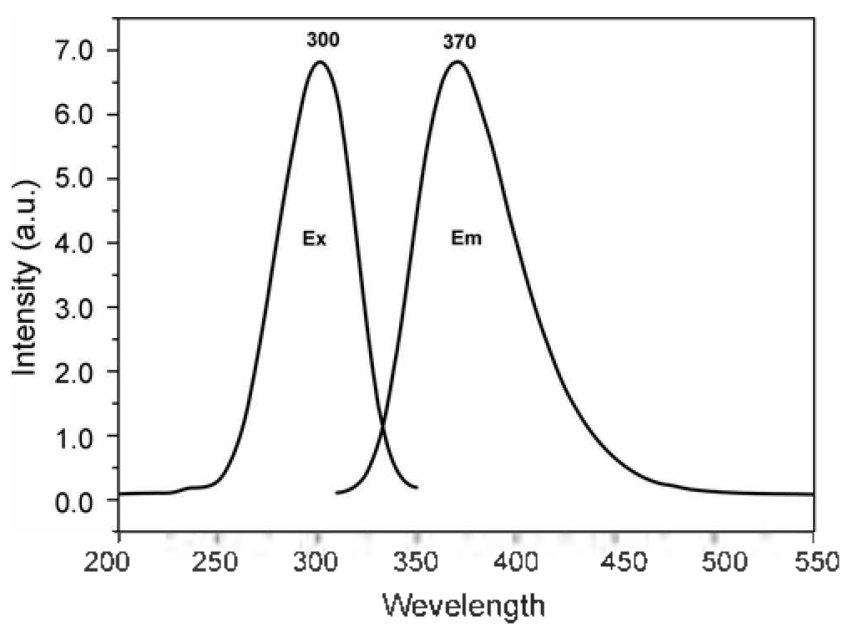

Figure 7. The spectrum of 12-4 in a methyl chloride (MC) solution.

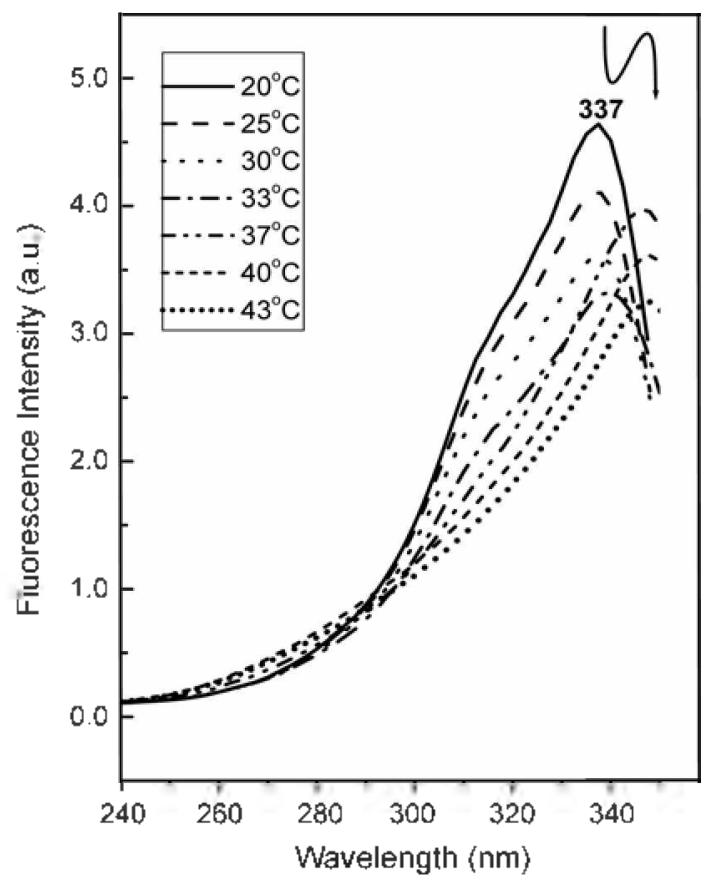

Figure 8. Temperature dependence of fluorescence excitation spectra for Pl2-4.

and then it abruptly goes up at $37^{\circ} \mathrm{C}$, the phase transition temperature (Figure 9). The abrupt increase in intensity at phase transition temperature is probably due to the new structure with a different quantum yield from that of crystalline phase. The discrete change in intensity may' imply that a quite different structure is formed at $\mathrm{K}-\mathrm{LC}$ transition as suggested in Raman results. where the $\mathrm{C}=\mathrm{O}$ and aromatic $\mathrm{C}-\mathrm{H}$ frequencies changed abruptly:

It is quite interesting to note that the fluorescence excitation shifts all the way to the longer wavelength with increasing temperature. This behavior is opposite to that of $12-4$. which reverts from the red shift to blue shift above LC temperature. It could imply that the monomer is not obtained for P12-4 even in a relatively high temperature above the phase transition temperature. indicating the intermolecular

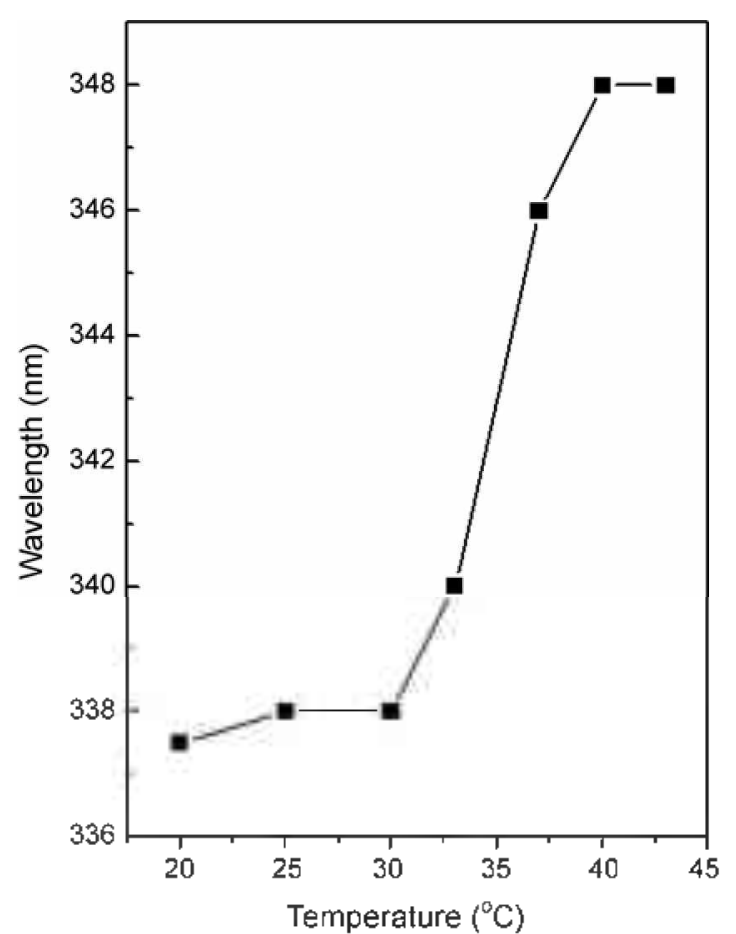

Figure 9. Temperature dependence of excitation peaks for P12-4.

ground state complex is quite different from each other. It is hard to explain the reason for not being detected the monomer form of $\mathrm{P} 12-4$ to the best of our knowledge.

From the Raman and Fluorescence studies we suggest the schematic diagram for the changes in the intermolecular interactions around the phase transition temperatures as shown in Figure 10.

\section{Conclusions}

The coil effects on the intermolecular structure in the crystalline phase were studied by observing the three Raman modes. $\mathrm{C}=\mathrm{O}$, aromatic $\mathrm{C}-\mathrm{H}$. and aromatic $\mathrm{C}=\mathrm{C}$. $\mathrm{PPO}$ and PEO coils are found to influence the intermolecular structures in a different way. The complementary results from the vibrational modes indicate that in P12-4 with PPO coils. the hydrogen bonding is induced through the carbonyl group between the biphenyl groups with the aromatic lydrogen atom of the adjacent molecule. In contrast. in 12-4 with PEO coils. the hydrogen bonding is induced through the carbonyl group near the ethyl terminal with the hydrogen of PEO coil of the adjacent molecule. Regardless of whether or not the intennolecular interaction can be assigned to a hydrogen bonding. our conclusion that PPO and PEO coils affect the molecular arrangement in a different way is still valid. The fluorescence studies also support the above arguments. The details in fluorescence excitation spectra for P12-4 and 12-4 are in good agreement with Raman data suggesting the mechanism for the structural changes during the phase transitions. These different arrangements in the crystalline phases may play an important role in making different LC structures. 


\section{$12-4$}

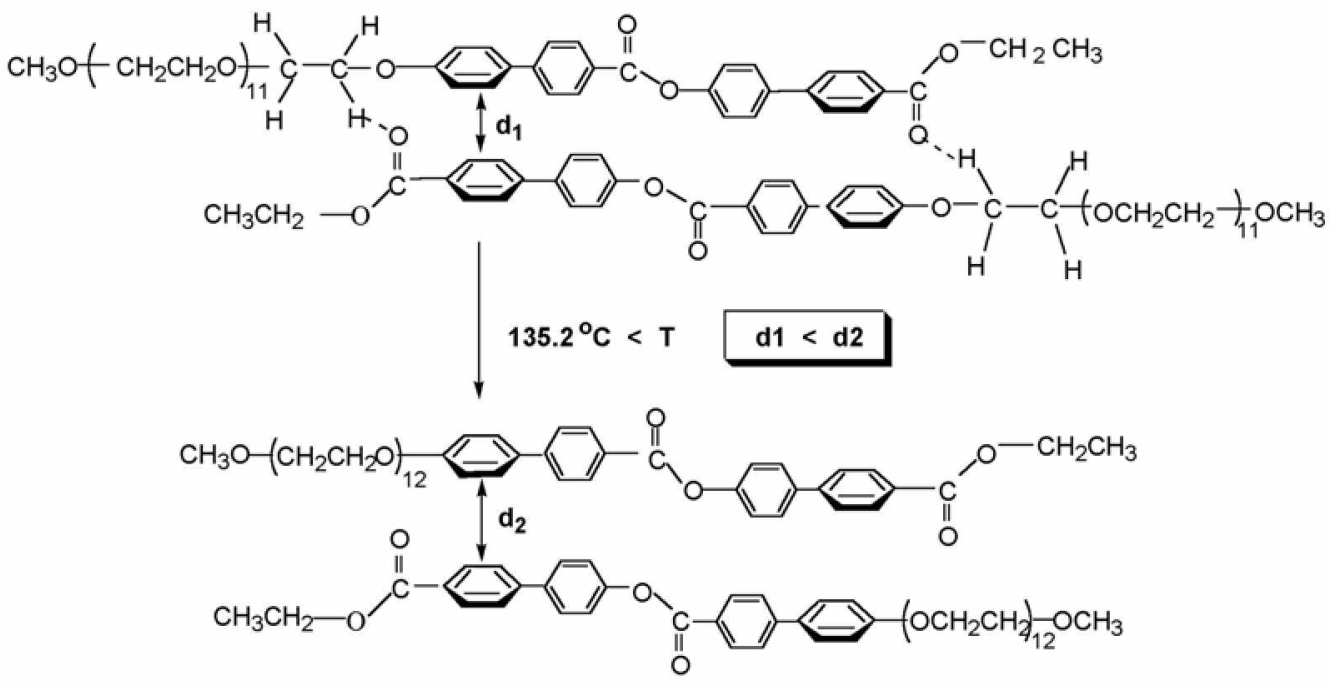

\section{P12 - 4}

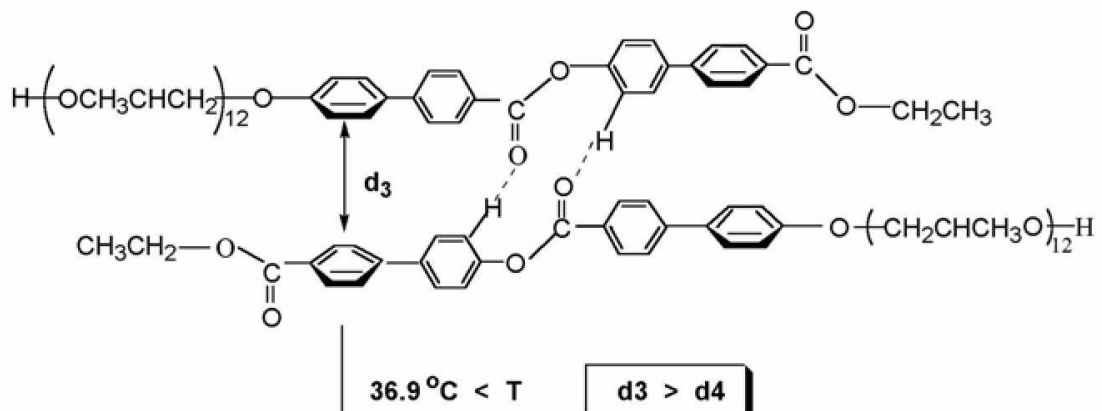

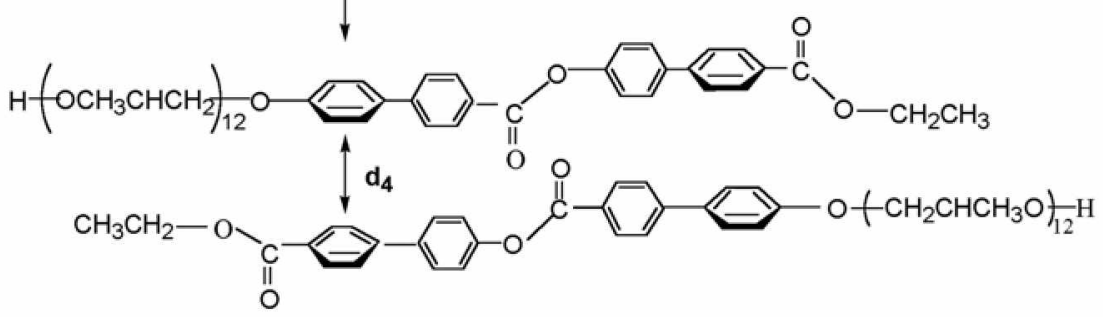

Figure 10. Schematic diagram for the intermolecular arrangements of $\mathrm{Pl} 2-4$ and $12-4$ before and after the phase transition temperatures. The distance between neighboring mesogens is designated by $\mathrm{d}_{i}(i=1,2,3,4)$.

Acknow ledgement. This work was financially supported by Kunsan National University's Long Tern Overseas Research Program for Faculty Member in the year 2005.

\section{References}

1. Halperin. A Hacromolecules 1990. 23, 2724.

2. Semenov. A. N. Mfol Cinst Liq. Crust 1991. 209.191.

3. Williams. D. R. M.: Fedrikson. G. H. Macromolecules 1992. 25.
3561 .

4. Dias. F. B.: Voss, J. P.; Batty. S. V.: Wright. P. V: Ungar, G Matromol Chem. Rapid Conmum. 1994. 15.961.

5. Lee. M.: Oh, N.-K. J. Mater: Chem 1996, 6, 1079

6. Lee. M.: Cho. B.-K.: Kim. H.: Yoon. J-Y.: Zin. W.C. J. An Chent. Soc. 1998. 120. 13258.

7. Bahadur. B. Liquid Crustals: Applications and Lses: World Scientific Publishing Co.: Singapore. 1990.

8. Huang. H. W: Horie, K. Tokita, M: Watanabe, J. Macromol Chem. Phus. 1998, 199. 1851. 
9. Huang. H. W.: Horie. K.: Yamashita. T.: Machida. S.: Sone. M.: Tokita. M.: Watanabe. J. Macrontolectles 1996. 29. 3485.

10. Takashi. H.: Horie. K.: Yamashita. T.: Machida. S.: Hannah. D. T. B.: Sherrington. D. C. Hacronol Chem Phys. 1996. 197.2703.

11. Horie. K. Huang. H. W. Macromol Symp. 1997. 118, 229.

12. Huang, H. W: Horie. K: Tokita. M.; Watanabe. J. Polymer 1999. 40,3013 .

13. Kim. H. Bull Forean Chem. Soc. 2006. 50.429.

14. Kroschwitz. I. I. Potwmers: Potwer Characterization and Anatysis: John Wiley \& Sons: New York. 1990.

15. Jume, J: Choo. J; Kim. D. J: Lee. S. Buhl Norean Chem. Soc. $2006,27,277$

16. Yu, S.-C: Choi, Y: Yu, K. H: Yu, J:Choi, H: Kim. D. H: Lee, M. Macronolectles 2000. 33.6527.

17. Wu. P. P.: Hsu. S. L.: Thomas. O.: Blumstein. A. J. Polvm Sci.: Part B. Polmer Physics 1986. 24.827.
18. Ellis, G.; Lprente, J.: Marco. C.: Gomez, M. A.: Fatou, J. G.; Hendra. P. T. Spectrochim Acta 1991. 47.4. 1353. and references therein.

19. Yu. K. H.: Rhee. J. M.: Lee. Y.: Lee. K.: Yu. S.-C. Langmit 2001. 17. 52 .

20. Park. B. Y; Jung. K. S.; Yu, S.-C.: Choi, H. S. J. Konan Chem. Soc. $\mathbf{2 0 0 3}, 77,309$.

21. Since the intensity of the hydrogen-bonded carbonyl mode is too low to monitor with temperature we monitored the fiee carbonyl mode at higher frequency. This is because its spectral behavior can be affected by the disruption of the conjugated form as the hydrogen bonding is broken down.

22. Briscoe. B. J.: Stuart. B. H.: Thomas, P. S.; Williams, D. R. Spectrochint Acta 1991. 47.t. 1299.

23. Hirschberg. T. G.: Vereb. G.: Meyer. C. K.: Kirsch. A. K.: Kohent. E.: Jovin. T. M. Applied Optics 1998, 37, 1953. 